\title{
Mycosis Fungoides and Sezary Syndrome N1 TNM Finding v7
}

National Cancer Institute

\section{Source}

National Cancer Institute. Mycosis Fungoides and Sezary Syndrome N1 TNM Finding v7. NCl Thesaurus. Code C88238.

Clinically abnormal peripheral lymph nodes; histopathology Dutch grade 1 or NCI LN0-2. Note: Dutch grade 1: dermatopathic lymphadenopathy. NCI LNO: no atypical lymphocytes. NCI LN1: occasional and isolated atypical lymphocytes (not arranged in clusters). NCI LN2: many atypical lymphocytes or in 3-6 cell clusters. (from AJCC 7th Ed.) 